1. Chobanian AV, et al. The Seventh Report of the Joint National Committee on Prevention, Detection, Evaluation, and Treatment of High Blood Pressure: the JNC 7 report. JAMA. 2003;289(19):2560-2572.

2. Dahl LK, Heine M. Primary role of renal homografts in setting chronic blood pressure levels in rats. Circ Res. 1975;36(6):692-696.

3. Bianchi G, Fox U, Di Francesco GF, Giovanetti AM, Pagetti D. Blood pressure changes produced by kidney cross-transplantation between spontaneously hypertensive rats and normotensive rats. Clin Sci Mol Med. 1974;47(5):435-448.

4. Grisk $\mathrm{O}$, et al. Long-term arterial pressure in spontaneously hypertensive rats is set by the kidney.
J Hypertens. 2002;20(1):131-138.

5. Crowley SD, et al. Angiotensin II causes hypertension and cardiac hypertrophy through its receptors in the kidney. Proc Natl Acad Sci U S A. 2006;103(47):17985-17990

6. Juillerat L, et al. Determinants of angiotensin II generation during converting enzyme inhibition. Hypertension. 1990;16(5):564-572.

7. Gonzalez-Villalobos RA, et al. The absence of intrarenal ACE protects against hypertension. J Clin Invest. 2013;123(5):2011-2023.

8. Gribouval O, et al. Spectrum of mutations in the renin-angiotensin system genes in autosomal recessive renal tubular dysgenesis. Hum Mutat.
2012;33(2):316-326

9. Matsusaka T, et al. Liver angiotensinogen is the primary source of renal angiotensin II. J Am Soc Nephrol. 2012;23(7):1181-1189.

10. Marc Y, Llorens-Cortes C. The role of the brain renin-angiotensin system in hypertension: implications for new treatment. Prog Neurobiol. 2011;95(2):89-103.

11. Foss JD, Fink GD, Osborn JW. Reversal of genetic salt-sensitive hypertension by targeted sympathetic ablation. Hypertension. 2013;61(4):806-811.

12. Persu A, Renkin J, Thijs L, Staessen JA. Renal denervation: ultima ratio or standard in treatment-resistant hypertension. Hypertension. 2012;60(3):596-606.

\title{
Anonymous sources: where do adult $\beta$ cells come from?
}

\author{
Michael S. German
}

Diabetes Center, Eli and Edythe Broad Center of Regeneration Medicine and Stem Cell Research, and Department of Medicine, UCSF, San Francisco, California, USA.

\begin{abstract}
Evidence that the pool of insulin-producing $\beta$ cells in the pancreas is reduced in both major forms of diabetes mellitus has led to efforts to understand $\beta$ cell turnover in the adult pancreas. Unfortunately, previous studies have reached opposing conclusions regarding the source of new $\beta$ cells during regeneration in the adult pancreas. In this issue of the JCI, Xiao et al. use a novel mouse model for detecting new $\beta$ cells derived from non- $\beta$ cells to demonstrate the absence of $\beta$ cell neogenesis from non- $\beta$ cells during normal postnatal growth and in models of $\beta$ cell regeneration. This work adds to mounting evidence that in most physiological and pathological conditions, $\beta$ cell neogenesis may not make large contributions to the postnatal $\beta$ cell pool - at least not in rodents.
\end{abstract}

We have long known that type 1 diabetes results from the autoimmune destruction of $\beta$ cells. More recently, a consensus has developed that the most common form of diabetes, type 2 diabetes, results from the failure of $\beta$ cells to compensate for increased insulin demand, which is associated with the increased calorie intake and decreased exercise that characterizes our modern life. Many factors may contribute to $\beta$ cell failure in type 2 diabetes, but the total number of $\beta$ cells, i.e., $\beta$ cell mass, is clearly one important contributor. At autopsy, $\beta$ cell mass varies substantially among young nondiabetic adults in the population, to a degree that exceeds the variation in height, weight, or BMI (1). Furthermore, $\beta$ cell mass is greater in set-

Conflict of interest: Michael S. German receives research support from Sanofi.

Citation for this article: J Clin Invest. 2013; 123(5):1936-1938. doi:10.1172/JCI69297. tings of increased insulin demand, such as pregnancy $(2,3)$ and obesity (4-8), suggesting some plasticity in the size of our $\beta$ cell pool. Most importantly, all studies to date have demonstrated that patients with type 2 diabetes have reduced $\beta$ cell mass, despite their increased insulin demand (4-9). It seems fairly obvious, therefore, that to understand the pathogenesis of diabetes and develop better therapies, we need to pool of $\beta$ cells, how much capacity we have as adults to generate new $\beta$ cells, and where those $\beta$ cells come from.

\section{Rodent models of $\beta$ cell generation give conflicting answers}

Unfortunately, we cannot measure $\beta$ cell mass in live humans, determine how that mass might change over time, or trace the source of any newly formed $\beta$ cells. Therefore, studies of $\beta$ cell growth and regeneration have turned to animal models, most understand what controls the size of our commonly that of rodents. During fetal development in rodents, $\beta$ cells differentiate from non $-\beta$ cell precursors through a process termed neogenesis (Figure 1). Studies in rodent embryos have worked out the pathways and genes involved in fetal neogenesis of $\beta$ cells (10). A critical step in this process is the decision by pancreatic progenitor cells to adopt an endocrine fate, as opposed to an acinar or duct cell fate. The transcription factor neurogenin 3 (NGN3, also known as Neurog3) controls the endocrine fate decision: its activation in scattered cells within the cords of pancreatic progenitor cells that form the fetal pancreatic ducts is both necessary and sufficient to drive their differentiation into endocrine cells (10). Because NGN3 expression is transient, it also acts as a useful marker of cells in the process of differentiating into endocrine cells, and the abundance of these NGN3-expressing endocrine progenitor cells is often used as a surrogate for the rate of fetal endocrine cell neogenesis.

Fetal neogenesis of $\beta$ cells in rodents stops at birth (11-14), but the newly differentiated $\beta$ cells, which are initially quiescent, start to proliferate rapidly, outstripping the overall growth rate and insulin requirement of the organism (15). This perinatal wave of proliferation also occurs in humans and causes a growth spurt in the $\beta$ cell population that establishes the size of the $\beta$ cell pool prior to the onset of puberty and adulthood (1). Once this wave 


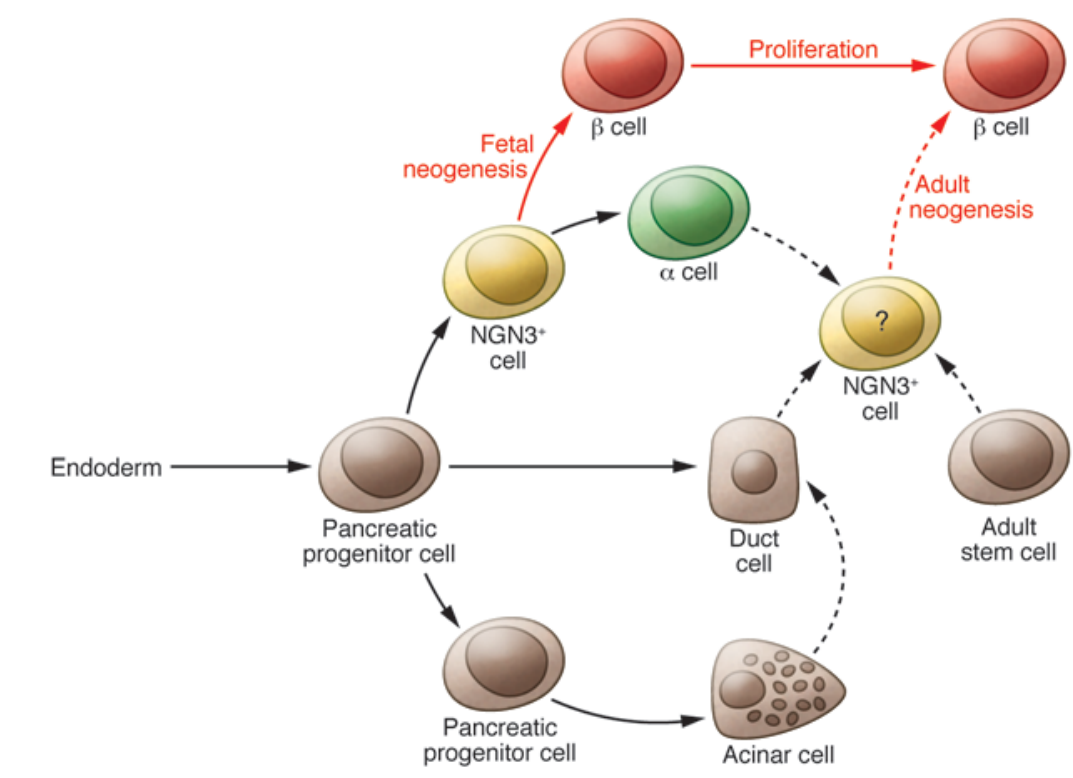

Fetal development

Adult regeneration

Figure 1

A model for $\beta$ cell generation and regeneration in mice. The dashed lines indicate proposed pathways for $\beta$ cell neogenesis in the adult mouse pancreas. The question mark indicates that perhaps not all of these proposed pathways for adult $\beta$ cell neogenesis pass through a transient NGN3+ intermediate.

passes, rates of $\beta$ cell proliferation drop dramatically and slowly decrease further with age in both humans and mice.

After the perinatal wave of proliferation, how much capacity does the mature pancreas retain to generate new $\beta$ cells? A long-standing literature has attested to the ability of the pancreas to increase $\beta$ cell mass in adults of multiple mammalian species in settings of increased insulin demand due to weight gain, glucose infusion, or pregnancy, and to regenerate $\beta$ cells in response to pancreatic damage or selective $\beta$ cell loss. In many of these studies, indirect evidence from morphological assessment and mathematical deduction based on differences between rates of proliferation and growth of the $\beta$ cell population supported the conclusion that neogenesis plays an important role in adult $\beta$ cell replacement, expansion, and regeneration (reviewed in refs. 16, 17). In 2004 , however, a prominent study changed the debate regarding sources of $\beta$ cells in the adult pancreas. Using a tamoxifen-inducible Cre recombinase transgene to permanently mark the existing $\beta$ cells in young adult mice, Dor et al. showed that most, if not all, of the $\beta$ cells present a year later descended from those initial $\beta$ cells and thus did not arise via neogenesis or transdifferentiation from a non- $\beta$ cell source (18). Further, Dor et al. found no evidence of substantial contributions from neogenesis to the regeneration of $\beta$ cell mass after partial pancreatectomy, although they could not rule out a small contribution, and they did not test other models of adult $\beta$ cell expansion or regeneration.

In contrast, in $2008 \mathrm{Xu}$ et al. reported the first explicit evidence of neogenesis in the adult mouse pancreas (19). They showed that partial duct ligation, a time-honored model of pancreatic damage (17), induced the formation of $\mathrm{NGN}^{+}$cells near the ducts of the damaged lobes of the ligated pancreas and that new functional $\beta$ cells derived from those $\mathrm{NGN3}^{+}$cells. Following this report, Inada et al. used a carbonic anhydrase II promoter to mark duct cells prior to duct ligation and showed that duct cells contributed to the generation of new $\beta$ cells after partial duct ligation (20). However, 2 subsequent studies using the $H n f 1 \beta$ (12) and Sox9 (14) promoters to genetically mark the duct cells and trace their descendents failed to show any contribution from duct cells to $\beta$ cell regeneration after partial duct ligation. A recent study from Pan et al. provides a potential explanation for these contradictory results by showing that the ductal NGN3 ${ }^{+}$cells identified in the partial duct ligation model actually originate from acinar cells that rapidly acquire characteristics of fetal pancreatic duct cells after duct ligation (21).

Interestingly, studies using a recently described mouse model of extreme $\beta$ cell loss that involves treatment with diphtheria toxin to selectively destroy $\beta$ cells expressing a human diphtheria toxin receptor transgene revealed a robust capacity for $\beta$ cell regeneration, but many of these new $\beta$ cells originated from glucagon-expressing $\alpha$ cells and not from Sox $9^{+}$duct cells $(22,23)$. In contrast, another group found that when the same diphtheria toxin receptor model was used to ablate all islet and acinar cells, $\beta$ cells regenerated from the remaining duct cells (24).

\section{A new assay for $\beta$ cell neogenesis in mice}

In the current issue, Xiao et al. readdress the question of whether new $\beta$ cells can be generated by neogenesis in the adult pancreas (25). In a novel aspect of this study, instead of directly determining the lineage of new $\beta$ cells by labeling potential precursor cell populations, the authors developed a system for marking any new $\beta$ cell derived from a non- $\beta$ cell. They employed a dual reporter system in which expression of Cre recombinase driven by the insulin promoter causes the deletion of a red fluorescent reporter and simultaneously activates a green fluorescent reporter. In the pancreas of these animals, if a red non$\beta$ cell differentiated into a $\beta$ cell (neogenesis), it would turn on the insulin gene and Cre recombinase. For a brief period, the overlap of red and green fluorescence would produce a yellow signal, until the red fluorescent protein degraded and the cell turned permanently green. Using these mice, they found that the developing fetal pancreas contained both yellow and green $\beta$ cells, but starting a few days after birth, only green $\beta$ cells were found, consistent with prior studies which demonstrated that the postnatal expansion of the $\beta$ cell pool comes from proliferation of preexisting $\beta$ cells, not from $\beta$ cell neogenesis.

The authors then addressed the issue of adult $\beta$ cell regeneration. Admirably, they tested multiple models of $\beta$ cell expansion and regeneration. In all of the models tested - pregnancy, $\beta$ cell ablation with $\beta$ cell toxins alloxan or streptozotocin, partial pancreatectomy, and duct 
ligation - they detected no evidence of significant $\beta$ cell neogenesis (25). Interestingly, a very recent report by Rankin et al. also supports the conclusion that partial pancreatic duct ligation does not induce $\beta$ cell neogenesis, and further, that there is no net increase in the $\beta$ cell population in the ligated lobe of the pancreas, regardless of the source (26).

Despite the lack of neogenesis, Xiao et al. did see activation of NGN3 in cells along the ducts after duct ligation (25), as others have reported $(14,19,21)$. Furthermore, they found that extracts from the damaged, ligated lobe of the pancreas could induce a marked increase in NGN3 expression in purified $\beta$ cells in culture. They concluded that signaling molecules related to the damage and extensive inflammation in the ligated lobe of the pancreas induce NGN3 expression, but not $\beta$ cell neogenesis.

\section{Conclusions}

So what conclusions can we draw other than the necessity for more studies? Former US Secretary of Defense Donald Rumsfeld once said of the hunt for weapons of mass destruction, "absence of evidence is not evidence of absence" (27). This is not strictly true, of course. Absence of evidence does provide evidence of absence, just not proof of absence. To prove that an event never occurs is tough. One could argue that evidence of the absence of $\beta$ cell neogenesis in the adult pancreas is mounting, but that conclusion disregards several well-performed studies that provided direct evidence of at least some adult $\beta$ cell neogenesis in mice and indirect evidence in humans (2, 6, 19-21, 24).

However, it should not be assumed that all partial pancreatectomy models or all duct ligation models are equivalent, as the degree and exact type of damage may depend on subtle differences in the surgery and these may impact the signaling events that ensue. The results from Xiao et al. showing that damage to the ligated lobe of the pancreas generates signals that induce NGN3 expression provides a possible explanation for these conflicting results: differences in the degree and type of damage might impact the maximum level of NGN3 induction and thus the capacity to induce neogenesis. A recent report stating that levels of NGN3 induction after duct ligation correlate with the probability of neogenesis supports this conclusion (28).

Finally, we have to remember that studies directly measuring neogenesis have never been performed in the most clinically relevant species: humans. Even if we definitively identify the cellular sources of $\beta$ cell regeneration in mice, there is good reason to believe that the same conclusion may not apply to humans (29). After more than a century of studying idiosyncratic models in other species, an important future goal for the field must be the development of improved tools for studying $\beta$ cell mass and regeneration in humans.

\section{Acknowledgments}

Thanks to members of the German laboratory for critical reading of the manuscript.

Address correspondence to: Michael S. German, UCSF Diabetes Center, University of California San Francisco, 35 Medical Center Way, RMB 1025, San Francisco, California 94143-0669, USA. Phone: 415.476.9262; Fax: 415.731.3612; E-mail: mgerman@diabetes.ucsf.edu.

1. Meier JJ, et al. $\beta$-cell replication is the primary mechanism subserving the postnatal expansion of $\beta$-cell mass in humans. Diabetes. 2008;57(6):1584-1594.

2. Butler AE, et al. Adaptive changes in pancreatic $\beta$ cell fractional area and $\beta$ cell turnover in human pregnancy. Diabetologia. 2010;53(10):2167-2176.

3. Van Assche FA, Aerts L, De Prins F. A morphological study of the endocrine pancreas in human pregnancy. BrJ Obstet Gynaecol. 1978;85(11):818-820.

4. Maclean N, Ogilvie RF. Quantitative estimation of the pancreatic islet tissue in diabetic subjects. Diabetes. 1955;4(5):367-376.

5. Kloppel G, Lohr M, Habich K, Oberholzer M, Heitz PU. Islet pathology and the pathogenesis of type 1 and type 2 diabetes mellitus revisited. Surv Synth Pathol Res. 1985;4(2):110-125.

6. Butler AE, Janson J, Bonner-Weir S, Ritzel R, Rizza RA, Butler PC. $\beta$-cell deficit and increased $\beta$-cell apoptosis in humans with type 2 diabetes. Diabetes. 2003;52(1):102-110.

7. Yoon $\mathrm{KH}$, et al. Selective $\beta$-cell loss and alphacell expansion in patients with type 2 diabetes mellitus in Korea. J Clin Endocrinol Metab. 2003; 88(5):2300-2308.

8. Rahier J, Guiot Y, Goebbels RM, Sempoux C, Henquin JC. Pancreatic $\beta$-cell mass in European subjects with type 2 diabetes. Diabetes Obes Metab. 2008;10(Suppl. 4):32-42.

9. Sakuraba H, Mizukami H, Yagihashi N, Wada R, Hanyu C, Yagihashi S. Reduced $\beta$-cell mass and expression of oxidative stress-related DNA damage in the islet of Japanese type II diabetic patients. Diabetologia. 2002;45(1):85-96.

10. Oliver-Krasinski JM, Stoffers DA. On the origin of the $\beta$ cell. Genes Dev. 2008;22(15):1998-2021.

11. Kopinke D, Murtaugh LC. Exocrine-to-endocrine differentiation is detectable only prior to birth in the uninjured mouse pancreas. BMC Dev Biol. 2010;10:38

12. Solar M, et al. Pancreatic exocrine duct cells give rise to insulin-producing $\beta$ cells during embryogenesis but not after birth. Dev Cell. 2009;17(6):849-860.

13. Furuyama $K$, et al. Continuous cell supply from a Sox9-expressing progenitor zone in adult liver, exocrine pancreas and intestine. Nat Genet. 2011;43(1):34-41

14. Kopp JL, et al. Sox $9^{+}$ductal cells are multipotent progenitors throughout development but do not produce new endocrine cells in the normal or injured adult pancreas. Development. 2011;138(4):653-665.

15. Finegood DT, Scaglia L, Bonner-Weir S. Dynamics of $\beta$-cell mass in the growing rat pancreas. Estimation with a simple mathematical model. Diabetes. 1995;44:249-256.

16. Bonner-Weir S, Li WC, Ouziel-Yahalom L, Guo L, Weir GC, Sharma A. $\beta$-cell growth and regeneration: replication is only part of the story. Diabetes. 2010;59(10):2340-2348

17. Granger A, Kushner JA. Cellular origins of $\beta$-cell regeneration: a legacy view of historical controversies. J Intern Med. 2009;266(4):325-338.

18. Dor Y, Brown J, Martinez OI, Melton DA. Adult pancreatic $\beta$-cells are formed by self-duplication rather than stem-cell differentiation. Nature. 2004;429(6987):41-46.

19. Xu X, et al. B cells can be generated from endogenous progenitors in injured adult mouse pancreas. Cell. 2008;132(2):197-207.

20. Inada A, et al. Carbonic anhydrase II-positive pancreatic cells are progenitors for both endocrine and exocrine pancreas after birth. Proc Natl Acad SciUS A. 2008;105(50):19915-19919.

21. Pan FC, et al. Spatiotemporal patterns of multipotentiality in Ptf1a-expressing cells during pancreas organogenesis and injury-induced facultative restoration. Development. 2013;140(4):751-764.

22 . Thorel F, et al. Conversion of adult pancreatic $\alpha$-cells to $\beta$-cells after extreme $\beta$-cell loss. Nature. 2010;464(7292):1149-1154.

23. Kopp JL, Dubois CL, Hao E, Thorel F, Herrera PL, Sander M. Progenitor cell domains in the developing and adult pancreas. Cell Cycle. 2011;10(12):1921-1927.

24. Criscimanna A, et al. Duct cells contribute to regeneration of endocrine and acinar cells following pancreatic damage in adult mice. Gastroenterology. 2011;141(4):1451-1462.

25. Xiao $X$, et al. No evidence for $\beta$ cell neogenesis in murine adult pancreas. J Clin Invest. 2013; 123(5):2207-2217.

26. Rankin MM, Wilbur CJ, Rak K, Shields EJ, Granger A, Kushner JA. Beta cells are not generated in pancreatic duct ligation induced injury in adult mice [published online ahead of print April 4, 2013]. Diabetes. doi:10.2337/db12-0848.

27. Rumsfeld DH. DoD News Briefing - Secretary Rumsfeld and Gen. Myers. US Department of Defense Web site. http://www.defense.gov/transcripts/transcript.aspx?transcriptid $=2636$. Updated February 12, 2002. Accessed March 26, 2013.

28. Van de Casteele $M$, et al. Neurogenin 3(+) cells contribute to $\beta$-cell neogenesis and proliferation in injured adult mouse pancreas. Cell Death Dis. 2013;4:e523.

29. Carlotti F, Zaldumbide A, Ellenbroek JH, Spijker HS, Hoeben RC, de Koning EJ. $\beta$-cell generation: can rodent studies be translated to humans? J Transplant. 2011;2011:892453. 